\title{
(C) OPEN ACCESS \\ Carotid dissection presenting as a prolonged cluster-like headache in a patient with episodic cluster headache
}

\author{
Ahmed Mohamed Elhfnawy, ${ }^{1}$ László Solymosi, ${ }^{2}$ Claudia Sommer ${ }^{1}$
}

${ }^{1}$ Department of Neurology, University Hospital of Würzburg, Würzburg, Bayern, Germany ${ }^{2}$ Department of Neuroradiology, University Hospital of Würzburg, Würzburg, Bavaria, Germany

\section{Correspondence to} Ahmed Mohamed Elhfnawy, Ahmedmelhfnawy@gmx.de

Accepted 6 July 2017
CrossMark

To cite: Elhfnawy AM, Solymosi L, Sommer C. BMJ Case Rep Published Online First: [please include Day Month Year]. doi:10.1136/ bcr-2017-220845

\section{SUMMARY}

We present a patient with known episodic cluster headache, who presented with cluster-like headache in the course of internal carotid artery dissection (ICAD) and discuss possible pathophysiological links between the two diseases. It is well known that cluster-like headache could be the presenting symptom of ICAD. However, ICAD occurring in a patient with a known episodic cluster headache was only once previously described. In the end of the manuscript, we propose red flags to help clinicians differentiate between primary cluster headache and cluster-like attacks masking underlying ICAD. Finally, we raise the question whether at least some proportion of those patients with cluster headache and Horner syndrome previously classified as a primary headache disorder might have been secondary cases to ICAD.

\section{BACKGROUND}

Headache and cervical pain are reported in 68\% and 39\%, respectively, in patients with internal carotid artery dissection (ICAD) and in 65\% and $66 \%$ in patients with vertebral artery dissection. ${ }^{1}$ These headaches are usually ipsilateral and have no specific characteristics. ${ }^{2}$ Migrainous features may be present. $^{23}$ Pain intensity in ICAD may range from mild to severe. ${ }^{3}$ Several cases of ICAD reported in the literature presented as a cluster-like headache. $^{3-8}$ ICAD complicating pre-existing episodic cluster headache was only once reported and represents a diagnostic dilemma. ${ }^{4}$ Carotid dissections may be missed in ultrasound examination, ${ }^{9}$ and the MRI sequences needed to discover ICAD (MR angiography, T1 axial cervical MRI with fat saturation) are usually not included in routine MRI examinations. ${ }^{26}$ Headache secondary to ICAD may even respond very well to sumatriptan, posing another diagnostic challenge. ${ }^{10}$ Headache is the most frequently reported symptom preceding the occurrence of cerebrovascular strokes in patients with ICAD. ${ }^{8}$ We raise the question whether cluster-like headache in ICAD is more common than previously thought.

\section{CASE PRESENTATION}

A 58-year-old-man with a 20-year history of episodic cluster headache presented in our neurological emergency room in December 2015 after an acute episode of severe neck pain. He had been pain free for several years until March 2015 when his headache recurred but responded well to a 3-week course of verapamil $240 \mathrm{mg}$ /day These recurrent headaches would occur on the left frontal side and were associated with lacrimation and redness of the eye as well as congestion of the nose. The patient described the pain as 'knife stabbing'. During the last 6 months, he had suffered from cracking noises in the neck. Three months ago, he had visited an orthopaedist who performed a twisting manoeuvre of his neck. Furthermore, the patient reported practising stretching manoeuvres of his neck on his own to relieve his neck tension. On presentation in our hospital in December 2015, the patient reported an episode of acute severe neck pain radiating to the right frontal region, with an intensity of $10 / 10$ on a numeric rating scale, that had already been present for 8 hours. The patient reported red eyes on both sides (right $>$ left), lacrimation on the right as well as right nasal congestion. Nausea, vomiting, photophobia, phonophobia or urgency to move were all denied. The patient had tried different analgesics including acetyl salicylic acid, ibuprofen, sumatriptan nasal spray as well as multiple $\mathrm{O}_{2}$ inhalations without effect. Finally, the pain remitted after admission to the ward. The patient reported to smoke 10 cigarettes per day and to drink alcohol rarely. Neurological examination was unremarkable except for minimal ptosis and miosis on the right (figure 1).

\section{INVESTIGATIONS}

Laboratory values including cerebrospinal fluid examination were normal. Also, extracranial and transcranial duplex sonography gave normal results. Cranial MRI and MRA revealed a haematoma in the wall of the right internal carotid artery in the distal part of the extracranial segment reaching to the petrous segment (figures 2 and 3 ).

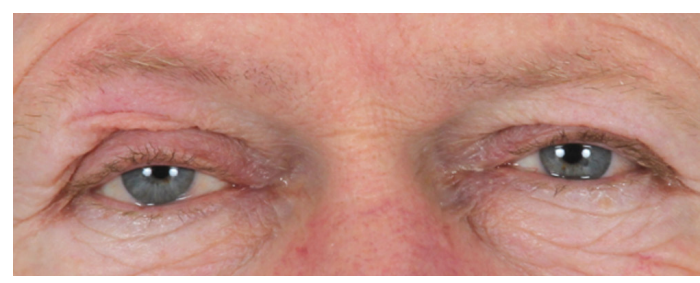

Figure 1 Patient photograph at presentation with ptosis and miosis on the right. 


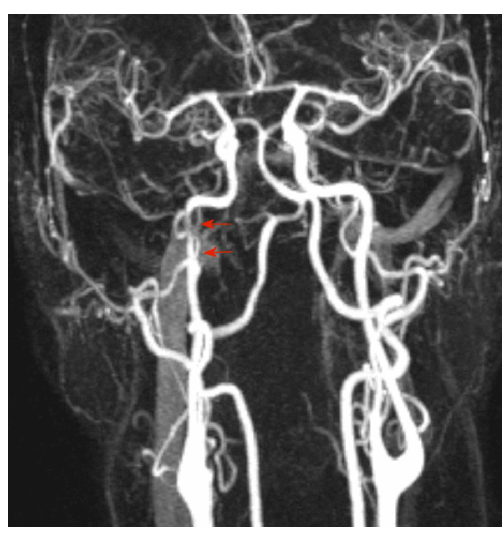

Figure 2 Time of flight MR angiography showing stenosis (arrows) of the extracranial internal carotid artery up to the petrous segment.

\section{DIFFERENTIAL DIAGNOSIS}

Based on the clinical examination without taking the neuroimaging into consideration, the differential diagnosis includes all causes of symptomatic cluster headache with an underlying structural lesion, which are listed below ${ }^{11}$ :

- arterial aneurysm

- arteriovenous malformation-/cavernous haemangioma

- subclavian steal syndrome

- carotid artery thrombosis

- cerebral venous thrombosis

- vertebral artery dissection

- pituitary tumours

- meningioma

- glioblastoma multiforme

- haemangiopericytoma

- nasopharynx carcinoma

- angiomyolipoma

- epidermoid tumour

- inflammatory myofibroblastic tumour

- lipoma

- arachnoid cyst

- sinusitis

- aspergilloma

- granolomatous pituitary involvement

- orbital pseudotumour

- cervical spinal epidural abscess

- multiple sclerosis

- foreign body in the maxillary sinus

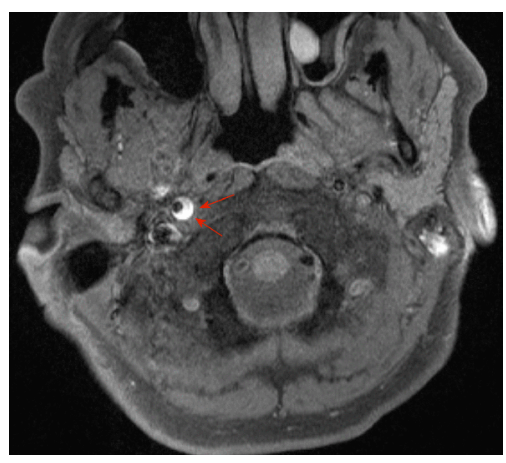

Figure 3 Axial T1w image with fat suppression showing wall haematoma (arrows) in the extracranial segment of the right internal carotid artery.
- cervical syringomyelia and Arnold-Chiari malformation

- sarcoidosis.

\section{TREATMENT}

The patient was placed on antiplatelet treatment with acetyl salicylic acid $100 \mathrm{mg}$ /day.

\section{OUTCOME AND FOLLOW-UP}

On 6 months follow-up, the patient was almost pain free and Horner syndrome had disappeared. The MRI and MR angiography examinations revealed regression of the pre-existing haematoma. After the follow-up visit, we recommended the discontinuation of acetyl salicylic acid.

\section{DISCUSSION}

Cluster headache attacks are pathognomonic with excruciating unilateral pain and the typical ipsilateral autonomic manifestations. ${ }^{12}$ However, symptomatic cluster headache mimics exist and need to be diagnosed. Horner syndrome occurs in around $22 \%$ of patients with cluster headache. ${ }^{13}$ On the other hand, Horner syndrome is reported to occur in $36 \%-58 \%$ of patients with ICAD. ${ }^{9}$

Horner syndrome occurs if the sympathetic pathway is interrupted along its long course from the hypothalamus to the oculosympathetic fibres. ${ }^{14}$ The first-order neurons originate from the hypothalamus and travel down the brainstem ipsilaterally to terminate at the ciliospinal centre at the level of C8-T2. The second-order neurons travel along the apex of the lung and end at the superior cervical ganglion at the carotid bifurcation. From the superior cervical ganglion, the third-order neurons travel along the carotid sheath to constitute the oculosympathetic fibres, which supply the ciliary muscle and the levator palpebrae superioris muscle.

It is assumed that activation of the postganglionic parasympathetic fibres occurs during the pain phase of cluster headache. ${ }^{15}$ These fibres emerge from the sphenopalatine ganglion and supply the lacrimal gland, meningeal sheaths and cranial blood vessels. It has been proposed that stretching of the sympathetic plexus in the internal carotid sheath as a result of parasympathetic vasodilatation would lead to failure of the oculosympathetic pathway and hence induce Horner syndrome. ${ }^{13} 15$ We speculate that excessive vasodilatation of the vasa vasorum and vasa nervorum, especially in the narrow carotid canal, might lead to extravasation and compression necrosis in the adventitia of the internal carotid artery resulting in ICAD. Thus, it might be speculated that processes inherent to cluster headache pathophysiology induce carotid dissection. This speculation is supported by the fact that in some cases, ICAD was diagnosed after a prolonged attack of headache occurring on top of classical new onset cluster headaches that had persisted for 2-4 weeks. ${ }^{16}$ We propose that cluster headache might occur as a primary event predisposing the wall of the ICA to the development of ICAD, either via the above-mentioned pathway or through a yet unknown pathophysiological mechanism. Furthermore, some authors found that in cluster headache, the sympathetic fibres in the cavernous sinus or carotid canal are especially affected. ${ }^{17}$ Interestingly, the segment of the carotid artery involved in our case as well as in the previous cases described in the literature with cluster headache, Horner syndrome and ICAD was the distal segment of the extracranial internal carotid artery or the transitional zone between the extracranial and intracranial internal carotid artery. ${ }^{4-816}$ A possible explanation is the 
presence of the oculosympathetic fibres around this segment which could be easily compromised in the carotid canal. It is to be stressed that this segment is also considered to be the sonographic blind segment and therefore special neuroimaging is warranted to unmask a hidden ICAD. ${ }^{9}$ However, ${ }^{4}$ the atypical features of the headache in a previously described case and in our case point to ICAD as the primary aetiology. Furthermore, the fact that the patient underwent a twisting manoeuvre and practised neck stretching exercises further support our hypothesis that ICAD was the primary aetiology.

We suggest the following red flags for symptomatic cluster headache: atypical type of headache, age $>40$ years at onset, prolonged duration of more than 3 hours or presence of ptosis and/or miosis. Horner syndrome may be a potentially helpful sign pointing to an underlying serious pathology, as it occurs in only one-fifth of the primary cluster headache patients. ${ }^{13}$ We raise the question whether at least some proportion of those patients with cluster headache and Horner syndrome previously classified as a primary headache disorder might have been secondary cases to ICAD. Dissection of the internal carotid artery could produce incomplete Horner syndrome consisting of ptosis or miosis without facial sweating because the fibres supplying the facial sweating travel along the external carotid artery. ${ }^{14}$ Therefore, the presence of facial sweating would be a reassuring sign. ${ }^{18}$ The decision to perform neuroimaging studies including MR angiography and axial MRI neck with fat suppression in every episode of cluster headache has to be made individually.

Learning points

- Carotid artery dissection (CAD) should be considered in patients with cluster headache if they have atypical features.

- Red flags for symptomatic cluster headache: atypical type of headache, age $>40$ years at onset or prolonged duration of more than 3 hours. Horner syndrome may be used as a potentially helpful sign pointing to an underlying serious pathology, as it occurs in only one-fifth of the primary cluster headache patients.

- The segment of the carotid artery involved in our case as well as in the previous cases described in the literature with cluster headache, Horner syndrome and internal CAD (ICAD) was the distal segment of the extracranial internal carotid artery or the transitional zone between the extracranial and intracranial internal carotid artery.

- It is to be stressed that this segment is also considered to be the sonographic blind segment, and therefore special neuroimaging is warranted to unmask a hidden ICAD.
Contributors All authors made substantial contribution to the conception, design and revision of the draft. AME was involved in the management and follow-up of the patient and wrote the manuscript. LS revised the manuscript and provided the MRI images. CS examined the patient and revised the manuscript. All authors were involved in the final approval of the version to be published.

Competing interests None declared.

\section{Patient consent Obtained.}

Provenance and peer review Not commissioned; externally peer reviewed.

Open Access This is an Open Access article distributed in accordance with the Creative Commons Attribution Non Commercial (CC BY-NC 4.0) license, which permits others to distribute, remix, adapt, build upon this work non-commercially, and license their derivative works on different terms, provided the original work is properly cited and the use is non-commercial. See: http://creativecommons.org/ licenses/by-nc/4.0/

(C) BMJ Publishing Group Ltd (unless otherwise stated in the text of the article) 2017. All rights reserved. No commercial use is permitted unless otherwise expressly granted.

\section{REFERENCES}

1 Debette S, Grond-Ginsbach C, Bodenant M, et al. Differential features of carotid and vertebral artery dissections: the CADISP study. Neurology 2011;77:1174-81.

2 Blum CA, Yaghi S. Cervical artery dissection: a review of the epidemiology, pathophysiology, treatment, and outcome. Arch Neurosci 2015;2:e26670.

3 Biousse V, D'Anglejan-Chatillon J, Massiou H, et al. Head pain in non-traumatic carotid artery dissection: a series of 65 patients. Cephalalgia 1994;14:33-6.

4 Candeloro $\mathrm{E}$, Canavero I, Maurelli $\mathrm{M}$, et al. Carotid dissection mimicking a new attack of cluster headache. J Headache Pain 2013;14:84.

5 Rigamonti A, lurlaro S, Reganati P, et al. Cluster headache and internal carotid artery dissection: two cases and review of the literature. Headache 2008;48:467-70.

6 Razvi SS, Walker L, Teasdale E, et al. Cluster headache due to internal carotid artery dissection. J Neurol 2006;253:661-3.

7 Weber R, Grab J, Berlit P, et al. Cluster-like headache due to dissection of the internal carotid artery after Pilates training. Nervenarzt 2014;85:474-5.

8 Godeiro-Junior C, Kuster GW, Felício AC, et al. Internal carotid artery dissection presenting as cluster headache. Arq Neuropsiquiatr 2008;66:763-4

9 Lee WW, Jensen ER. Bilateral internal carotid artery dissection due to trivial trauma. J Emerg Med 2000;19:35-41.

10 Leira EC, Cruz-Flores S, Leacock RO, et al. Sumatriptan can alleviate headaches due to carotid artery dissection. Headache 2001;41:590-1.

11 Edvardsson B. Symptomatic cluster headache: a review of 63 cases. Springerplus 2014;3:64

12 Headache Classification Committee of the International Headache Society (IHS). The International classification of Headache Disorders. 3rd edn (beta version). Cephalalgia, 2013;33:629-808.

13 Nieman EA, Hurwitz LJ. Ocular sympathetic palsy in periodic migrainous neuralgia. J Neurol Neurosurg Psychiatry 1961;24:369-73.

14 Flaherty PM, Flynn JM. Horner syndrome due to carotid dissection. J Emerg Med 2011:41:43-6

15 Alstadhaug KB, Ofte HK. Cluster headache. Tidsskr Nor Laegeforen 2015;135:1361-4.

16 Rigamonti A, lurlaro S, Zelioli A, et al. Two symptomatic cases of cluster headache associated with internal carotid artery dissection. Neurol Sci 2007;28(Suppl 1):S229-S231.

17 Drummond PD. Mechanisms of autonomic disturbance in the face during and between attacks of cluster headache. Cephalalgia 2006;26:633-41.

18 Frigerio S, Bühler R, Hess CW, et al. Symptomatic cluster headache in internal carotid artery dissection--consider anhidrosis. Headache 2003:43:896-900

Copyright 2017 BMJ Publishing Group. All rights reserved. For permission to reuse any of this content visit

http://group.bmj.com/group/rights-licensing/permissions.

BMJ Case Report Fellows may re-use this article for personal use and teaching without any further permission.

Become a Fellow of BMJ Case Reports today and you can:

- Submit as many cases as you like

- Enjoy fast sympathetic peer review and rapid publication of accepted articles

- Access all the published articles

- Re-use any of the published material for personal use and teaching without further permission

For information on Institutional Fellowships contact consortiasales@bmjgroup.com

Visit casereports.bmj.com for more articles like this and to become a Fellow 